\title{
Predicting relatedness and self-definition depressive experiences in aging women based on personality traits: A preliminary study
}

Joana Henriques-Calado, PhD candidate

Maria Eugénia Duarte-Silva, PhD

Rui C. Campos, PhD

Carlota Sacoto, MSc

Ana Marta Keong, MSc

Diana Junqueira, MSc

As part of the research relating personality and depression, this study seeks to predict depressive experiences in aging women according to Sidney Blatt's perspective based on the Five-Factor Model of Personality. The NEO-Five Factor Inventory and the Depressive Experiences Questionnaire were administered. The domains Neuroticism, Agreeableness, and Conscientiousness predicted self-criticism, explaining $68 \%$ of the variance; the domains Neuroticism and Extraversion predicted dependency, explaining $62 \%$ of the variance. The subfactors Neediness and Connectedness were differently related to personality traits. These findings are relevant to the research relating personality and anaclitic / introjective depressive experiences in late adulthood. (Bulletin of the Menninger Clinic, 77[3], 269-288)

Ms. Henriques-Calado, Dr. Duarte-Silva, Ms. Sacoto, Ms. Keong, and Ms. Junqueira are with the Faculty of Psychology, University of Lisbon, Portugal. Dr. Campos is with the Psychology Department, University of Évora, Portugal.

The authors want to thank all of the study participants. This work was supported by a doctoral grant from the Portuguese Foundation for Science and Technology (ref. SFRH/BD/44515/2008) awarded to the first author.

Correspondence may be sent to Joana Henriques-Calado, Faculty of Psychology, University of Lisbon, Alameda da Universidade 1649-013 Lisbon, Portugal; e-mail: joana. calado@netcabo.pt. Copyright (c) 2013 The Menninger Foundation) 